\title{
SOLID DISPERSION: STRATEGY TO ENHANCE SOLUBILITY
}

\author{
Dalvi P. B. ${ }^{1}$, Gerange A. B., ${ }^{1}$ Ingale P. R. ${ }^{2}$ \\ ${ }^{1}$ Department of pharmaceutics, SND College of Pharmacy, s Yeola, Nashik (MH), India \\ ${ }^{2}$ Women College Of Pharmacy, Chincholi, Nashik (MH), India \\ *Corresponding Author's email: amolgerange32@gmail.com, prashantdalvi26@gmail.com
}

Received 12 Jan 2015; Review Completed 12 Feb 2015; Accepted 10 March 2015, Available online 15 March 2015

\begin{abstract}
The solubility behavior of drugs remains one of the most exigent aspects in formulation development.With the advent of combinatorial chemistry and high throughput screening, the number of poorly water soluble compounds has dramatically increased. Among all the newly discovered chemical entities, about 40-45\% drugs fail to reach market due to their poor water solubility. Because of solubility problem, bioavailability of drugs gets affected and hence solubility enhancement becomes necessary. Solid dispersions have attracted considerable interest as an efficient means of improving the dissolution rate and hence the bioavailability of drugs. This article reviews the various preparation techniques, carriers used, advantages and limitations of solid dispersions and compiles some of the recent advances. There are various methods available to improve the solubility of the new drug in which solid dispersion emerged promising. A Solid dispersion generally composed of two components- the drug and the polymer matrix. Numerous methods are existing to prepare the solid dispersions such as melting method, solvent evaporation method, fusion method, kneading method, melting method, spray drying method, co-grinding method, lyophilization technique, hot melt extrusion, melt agglomeration, supercritical fluid (SCF) technology etc. Solid dispersion technologies are particularly promising for improving the oral absorption and bioavailability of BCS Class II drugs. The experience with solid dispersions over the last 10-15 years indicates that this is a very fruitful approach in improving the release rate and oral bioavailability of poorly water soluble drugs. Hence, this approach is expected to form a basis for the commercialization of many poorly water-soluble and water-insoluble drugs in their solid-dispersion formulations in the near future.
\end{abstract}

Key words: Dissolution, Solid Dispersion, Solubility, Cellulose Derivatives, Polyethylene glycol.

\section{INTRODUCTION}

Solubility is a significant physicochemical factor affecting absorption of drug and its therapeutic effectiveness. Formulation development would lead to be failure if drug having poor aqueous solubility. The low dissolution rate and low solubility of drug substances in water in aqueous G.I.T fluid frequently leads to inadequate bioavailability. The venture to improve the solubility and dissolution of hydrophobic drugs remain one of the dificult tasks in drug development. Several methods have been introduced to triumph over this problem. ${ }^{1}$

Various methods to increase the solubility of drugs are .available such as liquisolid, in which drug in solution state or dissolved drug is adsorbed over insoluble carriers $^{2}$

To improve wettability and solubility of various lipophilic substances surfactants can also be used in formulations. ${ }^{3}$ Micronization of drug is not ideal because micronized product has the propensity of agglomeration, which leads to reduced effective surface area for dissolution. But solid dispersion is the mainly promising method to formulators because of its simplicity of preparation, ease of optimization, and reproducibility $^{4}$ A poorly water soluble drug, more recently, has been defined in general terms to require more time to dissolve in the gastrointestinal fluid than it takes to be absorbed in the gastrointestinal tract. Drugs with low aqueous solubility have low dissolution rates and hence suffer from oral bioavailability problems. Model list of Essential Medicines of the World Health Organization (WHO) has assigned BCS (Biopharmaceutics Classification System) classification on the basis of data available in the public domain. Out of 130 orally administered drugs on the WHO list, 61 could be classified with certainty.

$84 \%$ of these drugs belong to class I (highly soluble, highly permeable)

$17 \%$ to class II (poorly soluble, highly permeable)

$39 \%$ to class III (highly soluble, poorly permeable) and

$10 \%$ to class IV (poorly soluble, poorly permeable)

The term solid dispersion refers to a group of solid products consisting of at least two different components, a hydrophilic matrix and a hydrophobic ISSN: 2250-1177
CODEN (USA): JDDTAO 
drug. The drug can be dispersed molecularly, in

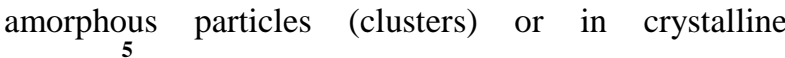
particles . Pharmaceutical polymers are used to create this matrix and their selection is based on many factors, including physicochemical (e.g. drug-polymer miscibility and stability) and pharmacokinetic (e.g. rate of absorption) constraints . Fig. 1 categorizes various possible categories of solid dispersions. The soliddispersion components consist mainly of active pharmaceutical ingredients (API), the polymer, plasticizers, stabilizers, and other agents.

Chiou and Riegelman defined the term solid dispersion as ${ }^{7}$ "A dispersion involving the formation of eutectic mixtures of drugs with water soluble carriers by melting of their physical mixtures"

Solid dispersion systems can increase dissolution rate and bioavailability of water insoluble drugs as when these are exposed to aqueous media, the carrier dissolves, and the drug is released as very fine colloidal particles. This greatly reduces particle size and increases surface area, which results in improved dissolution rates and per oral absorption. Furthermore, no energy is required to break up the crystal lattice of a drug during the dissolution process. Drug solubility and wettability may be increased by surrounding hydrophilic carriers ${ }^{8-9}$ This approach has been used for a variety of poorly soluble drugs such as nimesulide, ketoprofen, tenoxicam, nifedipine, nimodipine, ursodeoxycholic acid, carbamazepine, celecoxib and albendazole. Various hydrophilic carriers such as polyethylene glycol (PEG), polyvinylpyrrolidone (PVP), hydroxypropyl cellulose (HPC), hydroxypropylmethyl cellulose (HPMC), gums, sugar, mannitol, urea, hydroxypropylmethyl cellulose phthalate, gelucires, eudragits and chitosan have been investigated for improvement of dissolution characteristics and bioavailability of poorly aqueous soluble drugs 10

In solid dispersions, a portion of drug dissolves immediately to saturate the gastrointestinal tract fluid, and excess drug precipitates as fine colloidal particles or oily globules of submicron size. The development of solid dispersions as a practically viable method to enhance bioavailability of poorly water-soluble drugs overcame the limitations of previous approaches such as salt formation, Solubilization, cosolvency, and particle size reduction ${ }^{11}$. Based on their molecular arrangement, six different types of solid dispersions can be distinguished as described in Table 1 . Moreover, not the preparation method but the molecular arrangement governs the properties of solid dispersions.

\section{MATERIALS USED AS CARRIER FOR SOLID DISPERSIONS}

The selection of the carrier has the influence on the dissolution characteristics of the dispersed drug, since the dissolution rate of one component from the surface is affected by the other component in a multiple component mixture. Therefore, a water-soluble carrier results in a faster release of the drug from the matrix. A poorly soluble or insoluble carrier leads to slower release of a drug from the matrix. If the active drug present is a minor component in the dispersion, faster release of a drug can be achieved from matrix ${ }^{12,13,14}$. Various carriers used for preparation of solid dispersions are tabulated in Table 2.

Table 1: Materials used as carrier for solid dispersion

\begin{tabular}{|c|l|l|l|}
\hline S. No & Category & Carriers & Example \\
\hline 1 & Sugars & $\begin{array}{l}\text { Dextrose, sucrose, galactose, sorbitol, maltose, xylitol, } \\
\text { mannitol, lactose }\end{array}$ & $\begin{array}{l}\text { Rofecoxib from sorbitol } \\
\text { and mannitol }\end{array}$ \\
\hline 2 & Acids & Citric acid, succinic acid & $\begin{array}{l}\text { Felodipine, rofecoxib from } \\
\text { citric acid }\end{array}$ \\
\hline 3 & $\begin{array}{l}\text { Polymeric } \\
\text { materials }\end{array}$ & $\begin{array}{l}\text { Polyvinyl pyrrolidone(PVP), polyethylene glycol (PEG), } \\
\text { hydroxypropyl methyl cellulose (HPMC), methyl } \\
\text { cellulose (MC), hydroxy ethyl cellulose, cyclodextrin, } \\
\text { hydroxy propyl cellulose, pectin, galactomannan } \\
\text { etoricoxib rofecoxib from } \\
\text { PEG 4000 \& 6000 and } \\
\text { troglitazone and rofecoxib } \\
\text { from PVP K30 }\end{array}$ & $\begin{array}{l}\text { Indomethacin from } \\
\text { eudragit E100 }\end{array}$ \\
\hline 4 & $\begin{array}{l}\text { Insoluble or enteric } \\
\text { polymer }\end{array}$ & $\begin{array}{l}\text { Hydroxy propyl methyl cellulose phthalate (HPMCP), } \\
\text { eudragitL100, eudragit E100, eudragit RL, eudragit RS }\end{array}$ & $\begin{array}{l}\text { Felodipin and rofecoxib } \\
\text { from poloxamer 188 }\end{array}$ \\
\hline 6 & Murfactants & $\begin{array}{l}\text { Polyoxyethylene stearate, poloxamer 188, deoxycholic } \\
\text { acid, tweens, spans }\end{array}$ & Rofecoxib from urea \\
\hline
\end{tabular}

\section{ADVANTAGES OF SOLID DISPERSION}

The major advantage of solid dispersions is that it improves the dissolvability of a poorly water soluble drug in a pharmaceutical composition and results in rapid dissolution rates thereby improving the bioavailability of drug. Along with this, the approach may also offer others advantages which includes

\section{Rapid disintegration of oral tablets}

Drug is formulated with hydrophilic carrier (e.g. PEG) as a solid dispersion to increase its aqueous solubility and dissolution. Then superdisintegrant (e.g. 
croscarmellose sodium) is used in tablet formulation to achieve rapid disintegration of tablets prepared by wet granulation method. These rapidly disintegrating tablets can be used as an alternative to parenteral therapy enabling patient for self-medication even without the aid of water

\section{As a formulation vehicle}

Solid dispersions can be used as formulation vehicle to facilitate the preclinical safety and early clinical studies on new chemical entities with very low aqueous solubility. It provides a means to rapidly assess the safety and efficacy profile of the drug substance that may be otherwise difficult to obtain.

\section{Particles with reduced particle size}

Solid dispersions represent the last state on particle size reduction, and after carrier dissolution the drug is molecularly dispersed in the dissolution medium. Solid dispersions apply this principle to drug release by creating a mixture of a poorly water soluble drug and highly soluble carriers, thus a high surface area is formed, resulting in an increased dissolution rate and consequently improved bioavailability.

\section{Particles with improved wettability}

Enhancement of drug solubility is related to the drug wettability. It was observed that even carriers without any surface activity, such as urea improved drug wettability. Carriers with surface activity, such as cholic acid and bile salts when used, significantly increase the wettability of drug. Moreover, carriers can influence the drug dissolution profile by direct dissolution or cosolvent effects.

\section{Particles with higher porosity}

Particles in solid dispersions have been found to have a higher degree of porosity. Solid dispersions containing linear polymers produce larger and more porous particles than those containing reticular polymers and, therefore, results in a higher dissolution rate. The increased porosity of solid dispersion particles also hastens the drug release rate.

\section{Drugs in amorphous state}

The enhancement of drug release can usually be achieved if the drug in its amorphous state, because no energy is required to break up the crystal lattice during the dissolution process. In solid dispersions, drugs are presented as supersaturated solutions after system dissolution, and it is speculated that if drugs precipitate it is as a metastable polymorphic form with higher solubility than the most stable crystal form.

\section{Disadvantages of Solid Dispersion ${ }^{17}$}

1. Moreover, most of the polymers used in solid dispersions can absorb moisture, which may result in phase separation, crystal growth or conversion from the amorphous to the crystalline state or from a metastable crystalline form to a more stable structure during storage. This may result in decreased solubility and dissolution rate.

2. Drawback of solid dispersions is their poor scale-up for the purposes of manufacturing.

\section{Categories of solid dispersion}

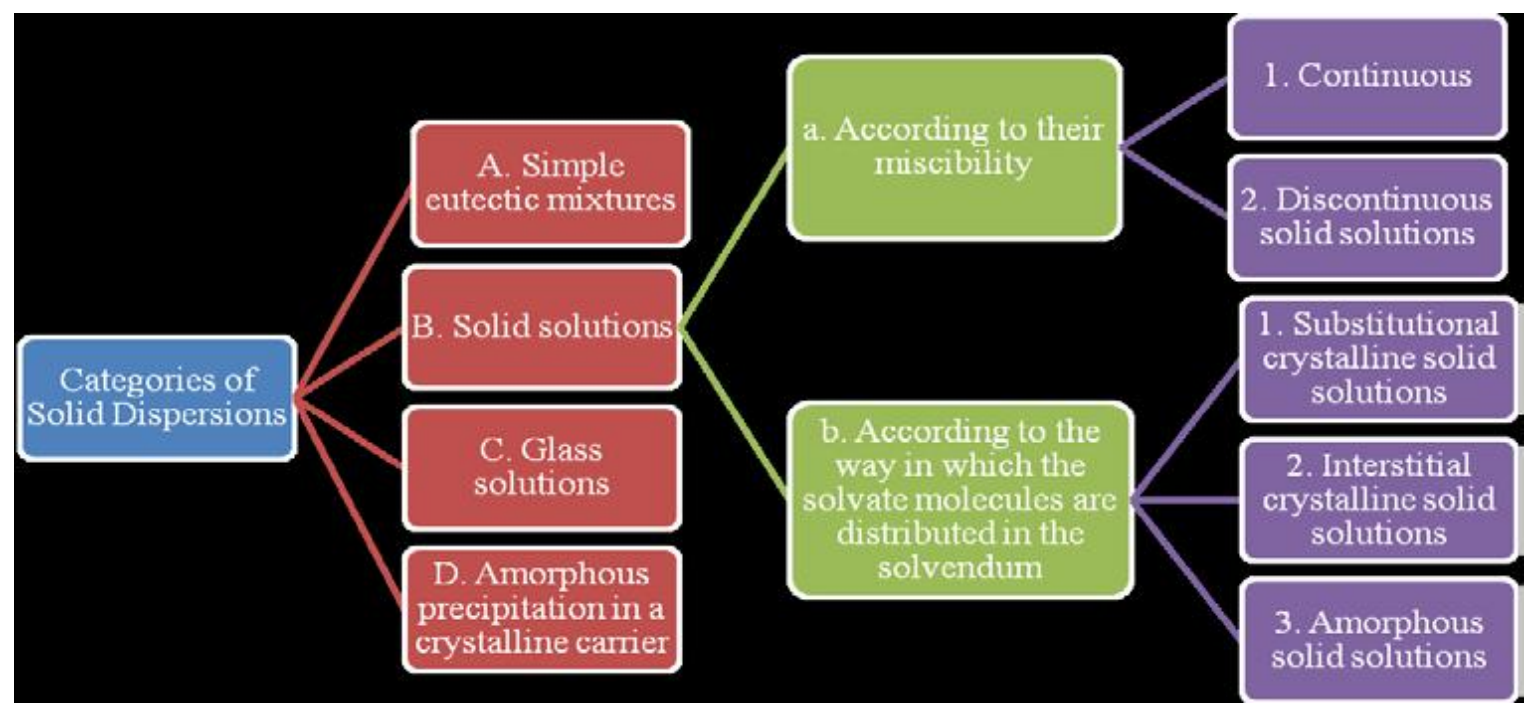

Fig. 1: Categories of solid dispersion

\section{METHODS OF PREPARATION OF SOLID DISPERSIONS}

Various methods have been developed for preparation of solid dispersions, these methods deal with the challenge of mixing a matrix and a drug, preferably on a molecular level, while matrix and drug are generally poorly miscible. During many of the preparation ¿ 2011-14, JDDT. All Rights Reserved techniques, demixing (partially or complete), and formation of different phases is observed. Phase separations like crystallization or formation of amorphous drug clusters are difficult to control and therefore unwanted. Various preparative methods are shown in Fig. 2.

The brief description of the methods is as follows: ISSN: 2250-1177

CODEN (USA): JDDTAO 


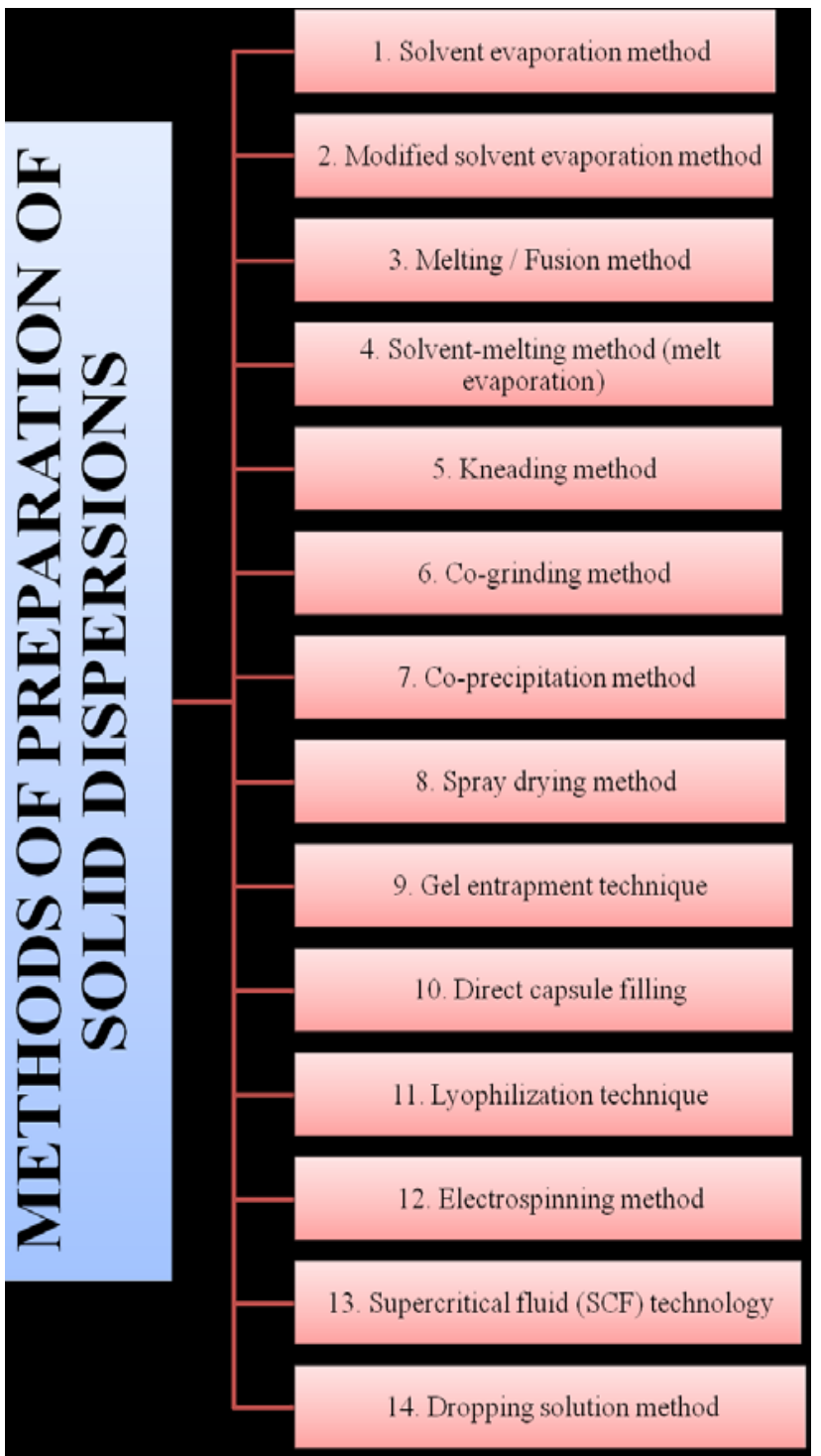

Fig. 2: Method of preparation of solid dispersions

\section{Solvent evaporation method}

In this method, the physical mixture of the drug and carrier is dissolved in a common solvent, which is evaporated until a clear, solvent free film is left. The film is further dried to constant weight. The main advantage of the solvent method is thermal decomposition of drugs or carriers can be prevented because of the relatively low temperatures required for the evaporation of organic solvents ${ }^{18}$.

However, some disadvantages are associated with this method such as

1) The higher cost of preparation.

2) The difficulty in completely removing liquid solvent.

3) The possible adverse effect of traces of the solvent on the chemical stability

4) The selection of a common volatile solvent.

5) The difficulty of reproducing crystal form.

6) In addition, a super saturation of the solute in the solid system cannot be attained except in a System showing highly viscous properties.

\section{Modified solvent evaporation method}

(c) 2011-14, JDDT. All Rights Reserved
Drug is dissolved in organic solvent at its saturation solubility with continuous stirring for some time. Polymer is suspended in sufficient amount of water (up to wet mass of polymer). The drug solution is poured at once into polymer suspension. The entire solvent is evaporated. The mass obtained is dried.

\section{Melting /Fusion method}

This method involves the preparation of physical mixture of a drug and a water soluble carrier and heating it directly until it melted. The melted mixture is then solidified rapidly in an ice-bath under vigorous stirring. The final solid mass is crushed, pulverized and sieved. The modification in the method can be done by pouring the homogenous melt in the form of a thin layer onto a ferrite plate or a stainless steel plate and cooled by flowing air or water on the opposite side of the plate. In addition, a super-saturation of a solute or drug in a system can often be obtained by quenching the melt rapidly from a high temperature. Under such conditions, the solute molecule is arrested in the solvent matrix by the instantaneous solidification process. The quenching technique gives a much finer dispersion of crystallites when used for simple eutectic mixtures ${ }^{19}$. Advantage of melting method is that it is economic and solventless process, however this method is not suitable for the drug or carrier which is unstable at fusion temperature or evaporates at higher temperature. Some of the means to overcome these problems could be by heating the physical mixture in a sealed container or melting it under vacuum or in presence of inert gas like nitrogen to prevent oxidative degradation of drug or carrier. E.g. Albendazole and urea solid dispersions were prepared by this method

\section{Kneading Technique}

In this method, carrier is permeated with water and transformed to paste. Drug is then added and kneaded for particular time. The kneaded mixture is then dried and passed through sieve if necessary.

\section{Co-precipitation method}

Required amount of drug is added to the solution of carrier. The system is kept under magnetic agitation and protected from the light. The formed precipitate is separated by vacuum filtration and dried at room temperature in order to avoid the loss of the structure water from the inclusion complex.

\section{Co-grinding method}

Physical mixture of drug and carrier is mixed for some time employing a blender at a particular speed. The mixture is then charged into the chamber of a vibration ball mill steel balls are added. The powder mixture is pulverized. Then the sample is collected and kept at room temperature in a screw capped glass vial until use. Ex. chlordiazepoxide and mannitol solid dispersion was prepared by this method. ${ }^{21}$

\section{Gel entrapment technique}

Hydroxyl propyl methyl cellulose is dissolved in organic solvent to form a clear and transparent gel. Then drug for example is dissolved in gel by sonication 
for few minutes. Organic solvent is evaporated under vacuum. Solid dispersions are reduced in size by mortar and sieved. ${ }^{22}$

\section{Spray-Drying Method}

Drug is dissolved in suitable solvent and the required amount of carrier is dissolved in water. Solutions are then mixed by sonication or other suitable method to produce a clear solution, which is then spray dried using spray dryer. $^{23}$

\section{Electrospinning}

Electrospinning is a process in which solid fibers are produced from a polymeric fluid stream solution or melt delivered through a millimeter-scale nozzle ${ }^{24}$.This process involves the application of a strong electrostatic field over a conductive capillary attaching to a reservoir containing a polymer solution or melt and a conductive collection screen. Upon increasing the electrostatic field strength up to but not exceeding a critical value, charge species accumulated on the surface of a pendant drop destabilize the hemispherical shape into a conical shape (commonly known as Taylor s cone). Beyond the critical value, a charged polymer jet is ejected from the apex of the cone (as a way of relieving the charge builtup on the surface of the pendant drop). The ejected charged jet is then carried to the collection screen via the electrostatic force.

The Coulombic repulsion force is responsible for the thinning of the charged jet during its trajectory to the collection screen. The thinning down of the charged jet is limited If the viscosity increases, the charged jet is dried $^{25}$. This technique has tremendous potential for the preparation of nanofibres and controlling the release of biomedicine, as it is simplest, the cheapest this technique can be utilized for the preparation of solid dispersions in future.

\section{Freeze-drying}

This process consists of dissolving the drug and carrier in a common solvent, which is immersed in liquid nitrogen until it is fully frozen. Then, the frozen solution is further lyophilized. Although it is concluded in literature that this is a promising and suitable technique to incorporate drug substances in stabilizing matrices, the technique is poorly exploited for the preparation of solid dispersions. An important advantage of freeze drying is that the drug is subjected to minimal thermal stress during the formation of the solid dispersion. However, the most important advantage of freeze drying is that the risk of phase separation is minimized as soon as the solution is vitrified. $^{26,27}$

\section{Supercritical fluid method}

Supercritical fluid methods are mostly applied with carbon dioxide (CO2), which is used as either a solvent for drug and matrix or as an anti-solvent36,37. This technique consists of dissolving the drug and the carrier in a common solvent that is introduced into a particle formation vessel through a nozzle, simultaneously with $\mathrm{CO} 2$. When the solution is sprayed, the solvent is rapidly extracted by the $\mathrm{SCF}$, resulting in the precipitation of solid dispersion particles on the walls and bottom of the vessel19. The use of processes using $\mathrm{SCF}$ reduces particle

size, residual solvent content, without any degradation and often results in high yield. ${ }^{28,29}$

\section{Melt Agglomeration Process}

The utility of the surfactant systems in solubilization is very important. Adsorption of surfactant on solid surface can modify their hydrophobicity, surface charge, and other key properties that govern interfacial processes such as flocculation/dispersion, floatation, wetting, solubilization, detergency, and enhanced oil recovery and corrosion inhibition. Surfactants have also been reported to cause solvation/plasticization, manifesting in reduction of melting the active pharmaceutical ingredients, glass transition temperature and the combined glass transition temperature of solid dispersions. Because of these unique properties, surfactants have attracted the attention of investigators for preparation of solid dispersions. ${ }^{\mathbf{3 0 , 3 1}}$

\section{Lyophilization Technique}

Lyophilization involves transfer of heat and mass to and from the product under preparation. This technique was proposed as an alternative technique to solvent evaporation. Lyophilization has been thought of a molecular mixing technique where the drug and carrier are co dissolved in a common solvent, frozen and sublimed to obtain a lyophilized molecular dispersion. ${ }^{32}$

\section{Dropping method solution}

The dropping method, developed by to facilitate the crystallization of different chemicals, is a new procedure for producing round particles from melted solid dispersions. This technique may overcome some of the difficulties inherent in the other methods. For laboratory-scale preparation, a solid dispersion of a melted drug-carrier mixture is pipette and then dropped onto a plate, where it solidifies into round particles. The use of carriers that solidify at room temperature may aid the dropping process. The dropping method not only simplifies the manufacturing process, but also gives a higher dissolution rate. It does not use organic solvents and, therefore, has none of the problems associated with solvent evaporation.

\section{Melt Extrusion Method}

Solid dispersion by this method is composed of active ingredient and carrier, and prepare by hot-stage extrusion using a co-rotating twin-screw extruder. The concentration of drug in the dispersions is always $40 \%$ (w/w). Melt extrusion technique is used in the preparation of diverse dosage forms in the pharmaceutical industry e.g. sustained-release pellets. ${ }^{33}$

\section{Direct capsule filling}

Direct filling of hard gelatin capsules with the liquid melt of solid dispersions avoids grinding-induced changes in the crystallinity of the drug ${ }^{34}$. This molten dispersion forms a solid plug inside the capsule on cooling to room temperature, reducing cross contamination and operator exposure in a dust-free 
environment, better fill weight and content uniformity was obtained than with the powder-fill technique. However, PEG was not a suitable carrier for the direct capsule-filling method as the water-soluble carrier dissolved more rapidly than the drug, resulting in drugrich layers formed over the surface of dissolving plugs, which prevented further dissolution of the drug. ${ }^{34}$

\section{Solvent melting method}

Accurately weighed drug is dissolved in organic solvent. The solution is incorporated into the melt of mannitol and cooled suddenly and mass is kept in desiccator for complete drying. The solidified mass is crushed, pulverized and passed through sieve. This technique possesses unique advantages of both the fusion and solvent evaporation methods. From a practical standpoint, it is only limited to drugs with a low therapeutic dose (less than $50 \mathrm{mg}$ ). ${ }^{35}$

\section{CHARACTERIZATION OF SOLID DISPERSIONS}

Several different molecular structures of the drug in the matrix can be encountered in solid dispersions. Several techniques have been available to investigate the molecular arrangement in solid dispersions. However, most effort has been put into differentiate between amorphous and crystalline material. Many techniques are available which detect the amount of crystalline material in the dispersion ${ }^{\mathbf{3 6}}$

\section{Drug -carrier miscibility}

- Hot stage microscopy

- Differential scanning calorimetry

- Powder X-ray diffraction

- NMR 1H Spin lattice relaxation time

\section{Drug carrier interactions}

- $\quad$ FT-IR spectroscopy

- Raman spectroscopy

- Solid state NMR

Physical Structure

- Scanning electron microscopy

- Surface area analysis

- Surface properties

- Dynamic vapor sorption

- Inverse gas chromatography

- Atomic force microscopy

- Raman microscopy

Amorphous content

- Polarised light optical microscopy

- Hot stage microscopy

- Humidity stage microscopy

- $\quad$ DSC (MTDSC)

- ITC

- Powder X-ray diffraction

Stability

- Humidity studies

- Isothermal Calorimetry

- $\quad$ DSC (Tg, Temperature recrystallization)
- Dynamic vapor sorption

- Saturated solubility studies

Dissolution enhancement

- Dissolution

- Intrinsic dissolution

- Dynamic solubility

- Dissolution in bio-relevant media

\section{Powder X-ray diffraction}

Powder X-ray diffraction can be used to qualitatively detect material with long range order. Sharper diffraction peaks indicate more crystalline material. ${ }^{37}$

\section{Infrared spectroscopy (IR)}

Infrared spectroscopy (IR) can be used to detect the variation in the energy distribution of interactions between drug and matrix. Sharp vibrational bands indicate crystallinity. Fourier Transformed Infrared Spectroscopy (FTIR) was used to accurately detect crystallinity ranging from 1 to $99 \%$ in pure material.

\section{Water vapour sorption}

Water vapour sorption can be used to discriminate between amorphous and crystalline material when the hygroscopicity is different. This method requires accurate data on the hygroscopicity of both completely crystalline and completely amorphous samples. ${ }^{\mathbf{3 8}}$

\section{Isothermal Microcalorimetry}

Isothermal microcalorimetry measures the crystallization energy of amorphous material that is heated above its glass transition temperature $(\mathrm{Tg})$. This technique has some limitations. Firstly, this technique can only be applied if the physical stability is such that only during the measurement crystallization takes place. Secondly, it has to be assumed that all amorphous material crystallizes. Thirdly, in a binary mixture of two amorphous compounds a distinction between crystallization energies of drug and matrix is difficult. ${ }^{39}$

\section{Dissolution calorimetry}

Dissolution calorimetry measures the energy of dissolution, which is dependent on the crystallinity of the sample. Usually, dissolution of crystalline material is endothermic, whereas dissolution of amorphous material is exothermic.

\section{Macroscopic techniques}

Macroscopic techniques that measure mechanical properties that are different amorphous and crystalline material can be indicative for the degree of crystallinity. Density measurements and Dynamic Mechanical Analysis (DMA) determine the modulus of elasticity for and viscosity and thus affected by the degree of crystallinity. However, also these techniques require knowledge about the additivity of these properties in intimately mixed binary solids. ${ }^{40}$

\section{Differential Scanning Calorimetry (DSC)}

Frequently used technique to detect the amount of crystalline material is Differential Scanning Calorimetry (DSC) . In DSC, samples are heated with a constant 
heating rate and the amount of energy necessary for that is detected. With DSC the temperatures at which thermal events occur can be detected. Thermal events can be a glass to rubber transition, (re)crystallization, melting or degradation. Furthermore, the melting- and (re)crystallization energy can be quantified. The melting energy can be used to detect the amount of crystalline material.

\section{Confocal Raman Spectroscopy}

Confocal Raman Spectroscopy is used to measure the homogeneity of the solid mixture. It is described that a standard deviation in drug content smaller than $10 \%$ was indicative of homogeneous distribution. Because of the pixel size of $2 \mu \mathrm{m} 3$, uncertainty remains about the presence of nano-sized amorphous drug particles.

\section{Temperature Modulated Differential Scanning Calorimetry (TMDSC)}

Temperature Modulated Differential Scanning Calorimetry (TMDSC) can be used to assess the degree of mixing of an incorporated drug. Due to the modulation, reversible and irreversible events can be separated. For example, glass transitions (reversible) are separated from crystallization or relaxation (irreversible) in amorphous materials. Furthermore, the value of the $\mathrm{Tg}$ is a function of the composition of the homogeneously mixed solid dispersion. It has been shown that the sensitivity of TMDSC is higher than conventional DSC. Therefore this technique can be used to assess the amount of molecularly dispersed drug. And from that the fraction of drug that is dispersed as separate molecules is calculated ${ }^{\mathbf{4 1}}$

\section{In Vitro Dissolution Studies}

In vitro dissolution studies are done for the find out dissolution behavior. The in-vitro dissolution study can be used to demonstrate the bioavailability or bioequivalence of the drug product through in vitro - in vivo correlation (IVIVC). On the other hand if absorption of the drug is dissolution rate limited that means the drug in the gastrointestinal fluid passes freely through the bio-membranes at a rate higher than it dissolves or is released from the dosage form. The specifically designed in-vivo dissolution study will be required in solid dispersion system to access the absorption rate, and hence its bioavailability and to demonstrate the bioequivalence ultimately. There are some apparatus used in United States pharmacopoeia for dissolution testing these are following. ${ }^{42}$

\section{Solubility Studies}

Solubility studies are done for the finding out the solubility behavior shown by the solid dispersion system in different types of solvent system and body fluids.

\section{MECHANISMS BEHIND IMPROVED DISSOLUTION}

The formulations of solid dispersions results into reduction in particle size, improved wettability and enhancement of the dispersibility of the drug, thereby markedly improving the dissolution rate. The suggested mechanism behind this tremendous increase in dissolution rate may include: ${ }^{\mathbf{4 3}}$

- Partial transformation of crystalline drug to the amorphous state or altering the crystalline morphology

- Formation of solid solution

- Formation of complexes

- Intimate mixing of the drug with hydrophilic excipients

- Reduction of aggregation and agglomeration

- Improved wetting of the drug and solubilization of drug by the carrier at the diffusion layer.

\section{Commercial Solid Dispersion Products}

In spite of almost several years of research on solid dispersions, their commercial application is limited. Only a few products have been marketed so far. Amongst these few are mentioned in Table $2 .{ }^{44,45}$

Table 2: Commercially marketed solid dispersions

\begin{tabular}{|c|l|l|l|}
\hline S. No & Commercial products & Polymer used & Manufacturer Company \\
\hline 1 & Gris-PEG® (Griseofulvin) & Polyvinylpyrrolidone (PVP) & VIP Pharma \\
\hline 2 & Intelence® (Etravirine) & Hypromellose, and microcrystalline cellulose & Tibotec, Yardley, PA \\
\hline 3 & Cesamet® (Nabilone) & Polyvinylpyrrolidone (PVP) & $\begin{array}{l}\text { Valeant Pharmaceuticals, } \\
\text { Costa Mesa, CA }\end{array}$ \\
\hline 4 & Sporanox ${ }^{\circledR}$ (Itraconazole) & Hydroxypropylmethyl cellulose (HPMC) & $\begin{array}{l}\text { Janssen Pharmaceutica, } \\
\text { Titusville, NJ }\end{array}$ \\
\hline 5 & lopinavir and ritonavir & Polyvinylpyrrolidone-vinyl acetate copolymer & $\begin{array}{l}\text { Abbott Laboratories, Abbott } \\
\text { Park, IL }\end{array}$ \\
\hline
\end{tabular}

\section{APPLICATIONS OF SOLID DISPERSION}

Solid dispersion systems can provide numerous additional benefits; some of them are as follows:

1. In improving immunosuppressive therapy in lung transplant patients, dry powder formulationconsisting of a solid dispersion (e.g. Cyclosporine A) for inhalation is prepared. It can avoid many problems like use of local anaesthesia and irritating solvents. 
2. Solid dispersion formulations were demonstrated to accelerate the onset of action for drugs such as nonsteroidal anti-inflammatory drugs (NSAIDS) where immediacy of action is crucial in relieving acute pain and inflammation.

3. Solid dispersion systems were shown to provide bio available oral dosage forms for anti-cancer drugs, which could be substituted for standard injections to improve patient comfort and compliance.

4. Solid dispersion systems were also found to reduce food effect on drug absorption, thus increasing the convenience of drug therapy as the need for some drugs to be taken with food was eliminated.

5. Solid dispersion- based dosage form allowed for greater drug loading per dose and improved stability over a soft gelatin capsule formulation which thereby improved the convenience of drug therapy by reducing the dosing regime and eliminating the need for refrigerated storage.

6. Improved absorption efficiency demonstrated for solid dispersion systems allows for a reduction in the content of active agent per dose, thus decreasing the cost associated with these drug therapies.

7. It also act as a functional carriers that offer the added benefit of targeting the release of highly soluble forms of poorly water soluble drugs to an optimum site for absorption.

These benefits demonstrate the current contributions and future potential of solid dispersion systems toward

\section{REFERENCES}

1. Leuner C, Dressman J. Improving drug solubility for oral delivery using solid dispersions. Eur J Pharm Biopharm 2000;50:47-60.

2. Nokhodchi A, Javadzadeh Y, Siahi-Shadbad MR, BarzegarJalali M. The effect of type and concentration of vehicles on the dissolution rate of a poorly soluble drug (indomethacin) from liquisolid compacts. J Pharm Pharm Sci 2005;8:1825.

3. Bakatselou V, Oppenheim RC, Dressman JB. Solubilization and wetting effects of bile salts on the dissolution of steroids. Pharm Res, 1991;8:1461-9.

4. Chiou WL, Reigelman S. Pharmaceutical applications of solid dispersion systems. J Pharm Sci 1971;60:1281-1302.

5. Dhirendra K. Solid dispersions: A review. Pak J Pharm Sci 2009; 22(2):234-246.

6. Doney J, Yang J, Baer H, Draganoiu E. Excipients in polymeric Drug Delivery and formulations. Pharm Tech. 2008:96-98.

7. Chiou WL, Riegelman S. Pharmaceutical application of solid dispersion system. J Pharm Sci 1971; 60:1281-1302. ): 603616.

8. Kerns EH, Li D. Drug-like properties: Concepts, structure, design and methods from ADME to toxicity optimization. Academic Press. 2008: 461.

9. Kalyanwat R, Patel S. Solid dispersion: A method for enhancing drug dissolution International Journal of Drug Formulation \& Research. Nov-Dec. 2010, Vol. 1 (iii):1-14.

10. Patel MV, Chen FJ. Solid carriers for improved delivery of active ingredients in pharmaceutical compositions. United States Patent Application 20030180352. 2003:1-46. improving drug therapies for a variety of important medical conditions whose treatment involves poorly water soluble drugs.

\section{Recent Advances \& Future Aspects}

Solid dispersion has great potential both for increasing the bioavailability of drug and developing controlled release preparations. Thus, to solve bioavailability issues with respect to poorly water-soluble drugs, solid dispersion technology has grown rapidly. The dosage form can be developed and prepared using small amounts of drugs substances in early stages of the drug development process, the system might have an advantage over such other commonly used bioavailability enhancement techniques as micronization of drugs and soft gelatin encapsulation.

\section{CONCLUSION}

The enhancement of oral bioavailability of poorly water soluble drugs remains one of the most challenging aspects of drug development. Dissolution of drug is the rate determining step for oral absorption of drugs, which can subsequently affect the in vivo absorption of drug. Because of solubility problem of many drugs the bioavailability of these gets affected and hence solubility enhancement becomes necessary. Solid dispersions are one of the most attractive processes to improve drug's poor water solubility. Various solubility enhancers like water-soluble carriers, co solvents, surfactants and superdisintegrants via solid dispersion approach (fusion method and solvent evaporation method) aids in solubility enhancement. These significantly help to improve the bioavailability and bioequivalence.

11. Chiou WL, Riegelman S. Pharmaceutical application of solid dispersion system. J Pharm Sci 1971; 60:1281-1302.

12. Ansel CH, Allen VL, Popovich AN, Pharmaceutical dosage forms and drug delivery systems. 7th edition 2000:248-252.

13. Patidar Kalpana, Soni Manish, Sharma K. Dinesh, Jain K. Surendra, Solid dispersion: Approaches, Technology involved, Unmet need \& Challenges, Drug Inv Today 2010; 2(7):349-357.

14. Vasconcelos T, Sarmento Costa B, P. Solid dispersions as strategy to improve oral bioavailability of poor water soluble drugs. Drug Discover Today.2007; 12(23-24):1068-1075.

15. Leuner C, Dressman J. Improving drug solubility for oral delivery using solid dispersions. Eur J Pharm Biopharm. 2000; 50(1):47-60

16. Babu PS, Chowdary KPR. Enhancement of dissolution rate of celecoxib by solid dispersion in superdisintegrants. Ind Drugs. 2008; 45(7):547-552.

17. Hume-Rotherly W, Raynor GV, The Structure of Metals and Alloys, Institute of Metals, London, 1954.

18. Serajuddin, A., 1999. Solid dispersion technique. $J$. Pharmaceut. Sci., 88 (10): 891-900.

19. Goldberg A, Gibaldi M, Kanig JL. Increasing dissolution rates and gastrointestinal absorption of drugs via solid solutions and eutectic mixtures III - experimental evaluation of griseofulvin- succinic acid solid solution. J Pharm Sci. 1966; 55: 487-492.

20. Kalaiselvan R, Mohanta GP, Manna PK, Manavalan R. Studies on mechanism of enhanced dissolution of albendazole solid dispersions with crystalline carriers. Ind J Pharm Sci. 2006; 68: 599-607. 
21. Nokhodchi A, Talari R, Valizadeh H, Jalali MB. An Investigation on the Solid Dispersions of Chlordiazepoxide. International Journal of Biomedical Science 2007;3(3):21016.

22. Bhise SB, Rajkumar M. Effect of HPMC on Solubility and Dissolution of Carbamazepine Form III in Simulated Gastrointestinal Fluids. Asian Journal of Pharmaceutics 2008;2(1):38-42.

23. Bakatselou V, Oppenheim RC, Dressman JB. Solubilization and wetting effects of bile salts on the dissolution of steroids. Pharm Res, 1991;8:1461-9.

24. Hohman, M.M, Shin, M., Rutledge, G., and Michael, P., 2001. Brenneraelectrospinning and electrically forced jets. II. Applications. Phys of fluids., 13(8): 2221-2236.

25. Neamnark, A., Rujiravanit, R., and Supaphol, P., 2006. Electrospinning of hexanoyl Chitosan. Carbohydrate polymers. Int. J. Pharmaceut.., 66: 298-305.

26. Drooge DJV, Characterization of the molecular distribution of drugs in glassy solid dispersions at the nano-meter scale, using differential scanning calorimetry and gravimetric water vapour sorption techniques, Int. J. Pharm, 310, 2006, 220 229.

27. Eriksson HJC, Hinrichs WLJ, Veen B, Somsen GW, Jong GJ, Frijlink HW, Investigations into the stabilisation of drugs by sugar glasses: I, Tablets prepared from stabilised alkaline phosphatase, Int. J. Pharm, 249(1-2), 2002, 59-70.

28. Majerik V, Bioavailability enhancement of an active substance by supercritical antisolvent precipitation, J. Supercrit. Fluids, 40, 2007,101-110.

29. Sethia S, Squillante E, Physicochemical characterization of solid dispersions of carbamazepine formulated by supercritical carbon dioxide and conventional solvent evaporation method, J. Pharm. Sci, 91, 2002, 1948-1957.

30. Ghebremeskel, A.N., Vemavarapu, C., and Lodaya, M., 2007. Use of surfactants as plasticizers in preparing solid dispersions of poorly soluble API: Selection of polymer surfactant combinations using solubility parameters and testing the processability. Int. J. Pharmaceu., 308: 119-129.

31. Zhang, R., and Somasundaran, P., 2006. Advances in adsorption of surfactants and their mixtures at solid/solution interfaces. Advances in colloid and interface science. Int. J. Pharmaceut., 123: 213-229.

32. Perissutti, B., Newton, J.M., Podezeck, F., and Rubessa, F., 2002. Preparation of extruded Carbamazepine and PEG 4000 as a potential rapid release dosage form. Europ. J. Pharmaceut. Biopharmaceut., 53: 125-132.
33. Karanth H, Shenoy VS, Murthy RR. 2006. Industrially feasible alternative approaches in the manufacture in the the solid dispersion: A technical report. AAPS PharmSciTech, 2006;7(4):87.

34. Serajuddin ATM, Sheen PC et al. Effect of vehicle amphiphilicity on the dissolution and bioavailability of a poorly water soluble drug from solid dispersions. J Pharm Sci. 1988; 77:414-417.

35. Patel MM, Patel DM. Fast dissolving valdecoxib tablets containing solid dispersion of valdecoxib. Ind J Pharm Sci. 2006: 222-225.

36. Kaushal, A.M, Guptam P., and Bansal, AK., 2004.Amorphous drug delivery systems: molecular aspects, design, and performance. Crit. Rev. There. Drug Carrier Syst., 21(3): 133-193.

37. Taylor, L.S., and Zografi, G., 1997. Spectroscopic characterization of interactions between PVP and indomethacin in amorphous molecular dispersions. Pharmaceut. Res., 14: 1691-1698.

38. Buckton, G., and Darcy, P., 1995. The use of gravimetric studies to assess the degree of crystallinity of predominantly crystalline powders. Int. J. Pharmaceut., 123: 265-271.

39. Sebhatu, T., Angberg, M., and Ahlneck, C., 1995. Assessment of the degree of disorder in crystalline solids by isothermal microcalorimetry. Int, J. Pharmaceut., 104: 135-144.

40. Pikal, M.J., Lukes, A.L., Lang, J.E., and Gaines, K., 1978. Quantitative crystallinity determinations for beta-lactam antibiotics by solution calorimetry: correlations with stability. J. Pharmaceut. Sci., 67(6): 767-73.

41. Demeuter, P., Rahier, H., and Van Mele, B., 1999. The use of modulated temperature differential scanning calorimetry for the characterisation of food systems. Int. J. Pharmaceut., 192(1): 77-84.

42. Cilurzo, F., Minghetti, P., Casiraghi, A., and Montanari, L., 2002. Characterization of nifedipine solid dispersions. Int. J. Pharmaceut., 242(1-2): 313-317.

43. Kalyanwat R, Patel S. Solid dispersion: A method for enhancing drug dissolution. Int J Drug Form Res. 2010; 1(3):1-14.

44. http://www.pharmatek.com/pdf/PTEKU/Jul302009.pdf. (Accessed - April 04, 2011).

45. http://www.genericsmed.com/buy-cheap-generic-grispeggriseofulvin-p-246.html.

46. Solid Dispersion Technologies: Williams RO, Taft DR, Conville JTM. In: Advanced drug formulation design to optimize therapeutic outcomes. 1 ed. Informa Health Care; 2007. p. 451-491 